evolving pattern of the physical and psychological responses to the pandemic is ongoing.

Acknowledgements: We would like to thank the Hibbs Lupus Trust.

Disclosure of Interests: None declared

DOI: 10.1136/annrheumdis-2021-eular.3246

\section{POS1242 \\ FACTORS ASSOCIATED WITH MORTALITY IN PATIENTS WITH RHEUMATIC DISEASES AND COVID-} 19 IN MEXICO

D. Alpizar-Rodriguez ${ }^{1}$, F. Irazoque-Palazuelos ${ }^{2}$, T. S. Rodriguez-Reyne ${ }^{3}$, E. Zamora ${ }^{4}$, D. X. Xibille Friedmann ${ }^{5}$, A. Castillo Ortiz ${ }^{6}$, M. U. MartínezMartínez $^{7}$, B. E. Zazueta ${ }^{8}$, S. Duran Barragan ${ }^{9}$, M. Rull-Gabayet ${ }^{3}$, M. Vázquez-Del Mercado Espinosa ${ }^{10}$, J. F. Moctezuma-Ríos ${ }^{11}$, A. BarragánGarfías $^{12}$, E. Martin-Nares ${ }^{3}$, D. Cervantes-Rosete ${ }^{3}$, D. Vega-Morales ${ }^{13}$, M. Aguiar Castellanos ${ }^{6}$, G. Reyes ${ }^{14}$, M. Macias ${ }^{15}$, L. V. Maya-Piña ${ }^{12}$ F. Cobos-Villanueva ${ }^{12}$, J. E. Navarro-Zarza ${ }^{16}$, A. Sanchez-Rodriguez ${ }^{12}$, M. D. P. Cruz-Domínguez ${ }^{12}$, X. Jimenez Jimenez ${ }^{12}, \mathrm{O}_{\text {. Marquez }}{ }^{17}, \mathrm{~A}$. Martínez ${ }^{12}$, A. Vargas Guerrero ${ }^{12}$, L. Andrade ${ }^{12}$, C. F. Pacheco Tena ${ }^{18}$ on behalf of Mexican Study group of COVID-19 in Rheumatic diseases. ${ }^{1}$ Colegio Mexicano de Reumatología, Research Unit, Mexico City, Mexico; ${ }^{2}$ Centro de Investigación y Tratamiento Reumatológico S.C., Rheumatology, Mexico City, Mexico; ${ }^{3}$ Instituto Nacional de Ciencias Médicas y Nutrición Salvador Zubiran, Immunology and Rheumatology, Mexico City, Mexico; ${ }^{4}$ Centro Médico de Pensiones, Rheumatology, Merida, Mexico; ${ }^{5}$ Servicios de Salud de Morelos, Departamento de Investigación y Capacitación,, Cuernavaca, Mexico; ${ }^{6}$ Private Practice, Rheumatology, Merida, Mexico; ${ }^{7}$ Instituto Mexicano del Seguro Social, Internal Medicine, Rioverde, Mexico; ${ }^{8}$ Private Practice, Rheumatology, Mexicali, Mexico; ${ }^{9}$ Clínica de Investigación en Reumatología y Obesidad, Rheumatology, Guadalajara, Mexico; ${ }^{10} \mathrm{Hospital}$ Civil de Guadalajara "Juan I. Menchaca”, Rheumatology, Guadalajara, Mexico; ${ }^{11}$ Hospital General de México 'Dr. Eduardo Liceaga', Rheumatology, Mexico City, Mexico; ${ }^{12}$ Private Practice, Rheumatology, Mexico City, Mexico; ${ }^{13}$ Private Practice, Rheumatology, Monterrey, Mexico; ${ }^{14}$ Private Practice, Rheumatology, Chihuahua, Mexico; ${ }^{15}$ Private Practice, Rheumatology, Veracruz, Mexico; ${ }^{16}$ Private Practice, Rheumatology, Chilpancingo, Mexico; ${ }^{17}$ Private Practice, Rheumatology, Campeche, Mexico; ${ }^{18}$ Facultad de Medicina y Ciencias Biomédicas, Rheumatology, Chihuahua, Mexico

Background: As of the 25th of January 2021, more than 150 thousand deaths as consequence of COVID-19 have been reported in Mexico [1]. Advanced age, male gender and comorbidities have been described as risk factors for severe disease and mortality in general population [2]. COVID-19 mortality in Mexican patients with rheumatic and musculoskeletal diseases (RMDs) is unknown.

Objectives: To describe characteristics of Mexican patients with RMDs and COVID-19, and to analyse factors associated with mortality.

Methods: The Global Rheumatology Alliance COVID-19 (GRA) physician reported registry, is an international effort to collect information on COVID19 in adult patients with RMDs. GRA is an observational registry. The first patient from Mexico was registered on April 17, 2020. All Mexican patients registered in GRA until October 30, 2020 were included in this analysis. The association of mortality with demographic and clinical variables was estimated using logistic regression analysis.

Results: A total of 323 patients were registered, with a median age of 52 (IQR 41-61) years old, 166 (51.4\%) patients lived in Mexico City. The most frequent RMDs were rheumatoid arthritis, 149 (46.1\%) and systemic lupus erythematosus, 24 (19.8\%). Over a third of patients with RMDs and COVID-19 (119 (36.8\%)) were hospitalized, and $43(13.3 \%)$ died. Table 1 shows clinical and demographic characteristics. In the univariable analysis, the absence of comorbidities was a protective factor, OR $0.3(95 \% \mathrm{Cl} 0.1-0.6)$. Factors associated with mortality at COVID-19 diagnosis were age over 65 years old, having type 2 diabetes, chronic renal insufficiency, treatment at COVID-19 diagnosis with corticosteroids or with CD20 inhibitors. In the multivariable adjusted analysis, these factors remained independently associated with mortality. No associations with other treatments or comorbidities at COVID-19 diagnosis were found.

Conclusion: Mexican patients with RMDs and COVID-19 in the GRA physician reported registry had a mortality of $13.3 \%$. Factors associated with mortality were those described in the general population, such as older age and being on corticosteroids and CD20 inhibitors treatment at COVID-19 diagnosis.

REFERENCES:

[1] WHO. Coronavirus disease (COVID-19) pandemic. https://www.who.int/ emergencies/diseases/novel-coronavirus-2019. (accessed 26 January, 2021).

[2] Zhou F, et al. Lancet 2020;395(10229):1054-62.
Table 1. Clinical and demographic characteristics of patients with rheumatic diseases and COVID-19 in Mexico and mortality.

\begin{tabular}{|c|c|c|c|c|c|}
\hline $\begin{array}{l}\text { Characteristics at COVID-19 } \\
\text { diagnosis }\end{array}$ & $\begin{array}{l}\text { Total } \\
\mathrm{N}=323\end{array}$ & $\begin{array}{l}\text { Death } \\
43(13.3)\end{array}$ & $\begin{array}{l}\text { Survivors } \\
280(86.7)\end{array}$ & $\begin{array}{l}\text { Univariable } \\
\text { OR }(95 \% \mathrm{Cl})\end{array}$ & $\begin{array}{l}\text { Multivariable } \\
\text { OR }(95 \% \mathrm{Cl})\end{array}$ \\
\hline Women, $\mathrm{n}(\%)$ & $\begin{array}{c}268 \\
(82.9)\end{array}$ & $33(76.7)$ & $235(83.9)$ & $0.6(0.3-1.4)$ & $0.5(0.2-1.3)$ \\
\hline $\begin{array}{l}\text { Age }>65 \text { years old, } n(\%) \\
\text { RMDs }^{*} n(\%)\end{array}$ & $62(19.2)$ & $18(41.9)$ & $44(15.7)$ & $3.9(1.9-7.7)$ & $\begin{array}{c}3.9(1.9-8.3) \\
-\end{array}$ \\
\hline Rheumatoid arthritis & $\begin{array}{c}149 \\
(46.1)\end{array}$ & $23(53.5)$ & $126(45.0)$ & $1.6(0.7-3.7)$ & - \\
\hline Systemic Lupus Erythemathosus & $64(19.8)$ & $10(23.3)$ & 54 (19.3) & $1.6(0.6-4.3)$ & - \\
\hline Spondyloarthritis (axial and others) & $33(10.2)$ & $2(4.7)$ & $31(11.1)$ & $0.1(0.1-2.8)$ & - \\
\hline Others & $77(23.8)$ & $8(18.6)$ & $69(24.6)$ & 1 & - \\
\hline $\begin{array}{l}\text { Moderate/High disease } \\
\text { activity }{ }^{1}, \mathrm{n}(\%)\end{array}$ & $57(18.6)$ & $7(17.9)$ & $50(18.7)$ & $1.0(0.4-2.5)$ & - \\
\hline None comorbidities, $\mathrm{n}(\%)$ & $\begin{array}{c}136 \\
(42.1)\end{array}$ & $8(18.6)$ & $128(45.7)$ & $0.3(0.1-0.6)$ & - \\
\hline Hypertension*, n(\%) & $88(27.2)$ & $12(27.9)$ & $76(27.1)$ & $1.0(0.5-2.1)$ & - \\
\hline Type 2 Diabetes*, n(\%) & $49(15.2)$ & $13(30.2)$ & $36(12.9)$ & $2.9(1.4-6.1)$ & $2.4(1.1-5.4)$ \\
\hline Obesity*, $n(\%)$ & $21(6.5)$ & $3(6.9)$ & $18(6.4)$ & $1.1(0.3-3.9)$ & - \\
\hline $\begin{array}{l}\text { Chronic obstructive pulmonary } \\
\text { disease }{ }^{\star}, \mathrm{n}(\%)\end{array}$ & $15(4.6)$ & $1(2.3)$ & $14(5.0)$ & $0.5(0.1-3.5)$ & - \\
\hline Chronic renal insufficiency ${ }^{\star}, \mathrm{n}(\%)$ & $17(5.2)$ & $6(13.9)$ & $11(3.9)$ & $3.9(1.4-11.4)$ & $3.4(1.1-10.4)$ \\
\hline Cardiovascular diseases ${ }^{\star}, \mathrm{n}(\%)$ & $14(4.3)$ & $2(4.7)$ & $12(4.3)$ & $1.1(0.2-5.0)$ & - \\
\hline Corticosteroids $^{\star}, \mathrm{n}(\%)$ & $\begin{array}{c}171 \\
(52.9)\end{array}$ & $30(69.7)$ & $141(50.3)$ & $2.3(1.1-4.5)$ & $3.0(1.4-6.5)$ \\
\hline CsDMARD*$^{*}, \mathrm{n}(\%)$ & $\begin{array}{c}247 \\
(76.5)\end{array}$ & $33(16.3)$ & $214(76.4)$ & $1.0(0.5-2.2)$ & - \\
\hline CD20 inhibitor ${ }^{\star}, \mathrm{n}(\%)$ & $21(6.5)$ & $7(16.3)$ & $14(5.0)$ & $3.7(1.4-9.9)$ & $4.9(1.7-14.5)$ \\
\hline
\end{tabular}

*Overlapped, ${ }^{1} 307$ patients.

Disclosure of Interests: None declared

DOI: 10.1136/annrheumdis-2021-eular.3342

\section{POS1243 AFFECTED BY GIANT CELL ARTERITIS DURING THE COVID-19 PANDEMIC - TELEMACOV}

S. Parisi ${ }^{1}$, M. C. Ditto ${ }^{1}$, A. Laganà ${ }^{1}$, C. L. Peroni ${ }^{1}$, E. Fusaro ${ }^{1} .{ }^{1}$ AOU Città della Salute e della Scienza di Torino, Rheumatology Unit, Turin, Italy

Background: Giant cell arteritis (GCA) is the most common primary systemic vasculitis in western countries with the highest incidence among persons $70-79$ years of age. Treatment has been with glucocorticoids (GCs) alone for many decades but recently Tocilizumab (TCZ) has demonstrated efficacy in reducing GC dose and flare rates in patients with GCA. Therefore, both early diagnosis and regular monitoring are necessary for the correct management of GCA. The COVID-19 pandemic has led to decisions by the governments of the countries involved, aimed above all at reducing the contagion. This has also led to reductions in health activities, limiting them to those of urgency by reducing or canceling checkups involving the risk of a time gap which for the GCA meant the interruption of clinical monitoring and therapeutic adjustment. At the same time, the pandemic situation has stimulated remote monitoring activities, through telephone contacts or video calls carried out by the rheumatologist. EULAR identified a minimal data set aimed at research and for clinical use, which includes the main clinical and instrumental data to be taken into consideration in monitoring the patient. For many data a clinical examination is not necessary but an interview is sufficient. We activated the TELEMACOV protocol (TELEmedicine and Management of the patient affected by giant cell arteritis during the COVid-19 pandemic) monitor ing the follow-up of patients affected by GCA through telemedicine tools in order to maintain an effective and risk-free follow-up in a pathology with a high risk of relapse. Objectives: The purpose of the study is to evaluate the effectiveness of telemedicine in the follow-up of the patient with GCA.

Methods: We evaluated patients (pts) with a clinical diagnosis of GCA (received in previous periods) who were admitted to the our Rheumatology Unit. They were monitored monthly by telephone from 9 March to 9 June 2020 (during lockdown). All patients were asked questions divided according to the sub-groups listed below:

Onset of new symptoms or their recurrence

- Exams carried out

Current therapy

- Satisfaction of telephone call

Results: We performed 148 remote monitoring visits in 37 pts. The cohort was mainly composed by female $(77,8 \%)$ and had a mean age of $71,85 \pm 9,25$ years. They were affected by GCA, with a mean duration of $5,3 \pm 2,3$ months. The characteristics of these pts and the course of the disease are reported in Table 1. Pts treated with TCZ reduced their GC dose more than patients treated with GC alone (p: 0.032). Only one patient (treated with GC alone) had an ocular flare with the need to increase the dosage of the $\mathrm{GC}$ with good response and rapid 
improvement. Furthermore, all patients considered this type of monitoring very satisfactory according to the Likert scale (1-5) with mean 4,4 40,2 .

Conclusion: Our study has shown how telemedicine can be well used in pts with GCA as a possible alternative, for a limited period, to traditional visits, especially in a fragile population such as the elderly and more exposed to the risk of SARSCOV2 infection.

REFERENCES:

[1] Ehlers L et al. Ann Rheum Dis 2019 Sep;78(9):1160-1166

[2] Wagner E et al. Prim Care. 2012 Jun;39(2):241-59.

Table 1. Disease course and remote monitoring

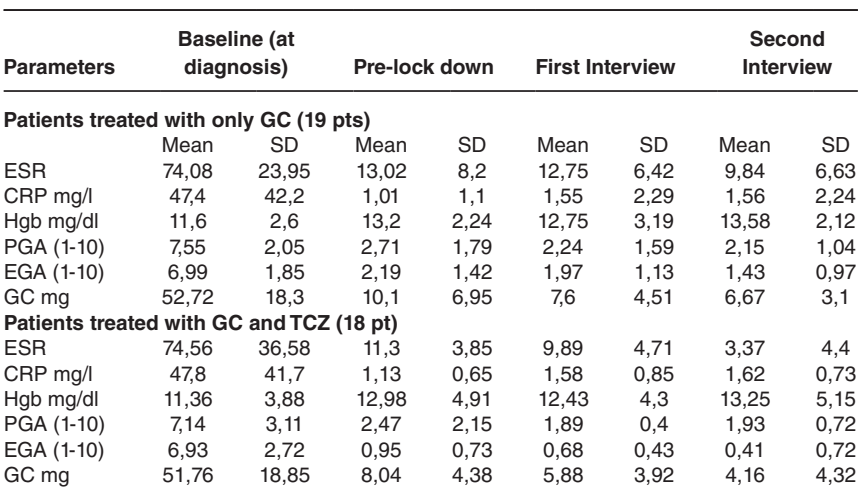

PGA: Patient Global Assessment EGA: Evaluator Global Assessment;

Disclosure of Interests: None declared

DOI: 10.1136/annrheumdis-2021-eular.3357

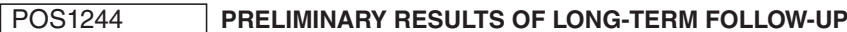 OF THE HEALTH STATUS OF PATIENTS USING CSDMARDS AND B/TSDMARDS FOR RHEUMATIC DISEASES DURING THE COVID-19 PANDEMIC}

F. Unlu Ozkan ${ }^{1}$, K. Sari ${ }^{1}$, I. Aktas ${ }^{1} .{ }^{1}$ University of Health Sciences Fatih Sultan Mehmet Training and Research Hospital, Physical Medicine and Rehabilitation, Istanbul, Turkey

Background: Since its inception, the COVID-19 outbreak has been carefully monitored both by the patients using DMARDs and their physicians. There is no data that patients with rheumatic and musculoskeletal diseases (RMD) are at a higher risk of contracting COVID-19 disease than those without RMD (1). COVID-19-related death in people with RMD has been associated with older

Table 1. Patient characteristics

\begin{tabular}{lcc}
\hline & All Patients $\mathrm{n}=160$ & COVID-19 Patients $\mathrm{n}=24$ \\
\hline Male & $61(38 \%)$ & $6(25 \%)$ \\
Female & $99(62 \%)$ & $18(75 \%)$ \\
Mean age & 49.5 & 49.5 \\
Ever smoker & $88(55 \%)$ & $8(33,3 \%)$ \\
Obesity & $51(32 \%)$ & $9(37,5 \%)$ \\
Hypertension (HT) & $46(29 \%)$ & $7(29 \%)$ \\
Diabetes (DM) & $22(14 \%)$ & $2(8 \%)$ \\
Cardiovascular disease (CVD) & $26(16 \%)$ & $5(20 \%)$ \\
Chronic lung disease (CLD) & $12(7,5 \%)$ & $4(16 \%)$ \\
SpA & $71(44,3 \%)$ & $9(37,5 \%)$ \\
RA & $71(44,3 \%)$ & $14(58,3 \%)$ \\
PsA & $14(8,8 \%)$ & $1(4,2 \%)$ \\
SLE & $2(1,25 \%)$ & - \\
PMR & $2(1,25 \%)$ & - \\
cDMARD only & $82(51,2 \%)$ & $14(58,3 \%)$ \\
b/tsDMARD only & $55(34,4 \%)$ & $8(33.3 \%)$ \\
Combined DMARD & $23(14,4 \%)$ & $2(8.4 \%)$ \\
\hline
\end{tabular}

The rate of getting COVID-19 infection was $15 \%$ in all patients. This rate was $18 \%$ in all obese patients, $19 \%$ in those with at least one comorbid disease (HT, DM, CVD, CLD), and $22 \%$ in those who were obese and had at least one comorbid disease. $16 \%$ of non-smokers and $9 \%$ of those who ever smoked got COVID-19. Among patients over the age of $65(n=17), 2$ patients (\%12) had COVID-19. Treatments of RMDs of patients with COVID-19 were as follows: bDMARD $=8[($ Etanercept $(E T N) n=2$, adalimumab (ADA) $n=2$, certolizumab pegol $(C T Z)$ $n=1$, infliximab (IFX) $n=1$, golimumab (GOL) $n=1, R T X n=1)$ ], csDMARD=14 [(methotrexate (MTX) $n=4$, leflunomid (LEF) $n=4, S S Z n=3, H C Q n=2, M T X+S S Z+H C Q n=1$ )], combined=2 [tofacitinib (TOF)+MTX $n=1, T C Z+L E F n=1$ )], none of them was using glucocorticoids. Overall $17 \%$ of patients using csDMARD, $14,5 \%$ of patients using b/tsDMARD as monotherapy and $9 \%$ of patients using combination treatment had COVID-19. Of the patients using HCQ $(n=14)$, $3(21 \%)$ were diagnosed with COVID-19 disease. 18 of the patients received COVID-19 treatment at home, 6 were hospitalized and 1 of them (RA patient, LEF user) needed intensive care unit. None of them died. age, male gender, concomitant cardiovascular and pulmonary diseases, moderate/high disease activity, and certain treatments (rituximab (RTX), sulfasalazine (SSZ) and some immunosuppressants) (2).

Objectives: To determine the conditions of getting and being affected poorly by COVID-19 and related factors of RMD patients followed in our outpatient clinic. Methods: 160 patients over 18 years of age who applied to our outpatient clinic between July 2020-January 2021; who used DMARDs for rheumatic diseases and agreed to participate were included in the study. The patients's demographic data, RMDs, csDMARDs and b/tsDMARDs usage, comorbid dis eases and smoking status were recorded. The data of the patients on COVID 19 disease between March 2020 and January 2021 were questioned at each visit.

Results: Patient characteristics are presented in Table $1.57(36 \%)$ of all patients had COVID-19 PCR test, 23 (14\%) were positive, and 1 patient was diagnosed with COVID-19 because the CT findings were positive, although the PCR test was negative.

Conclusion: Preliminary results regarding the health status associated with COVID-19 of our patients with RMD are presented. Biologic drugs seems not to increase COVID-19 but final results will be presented after the completion of statistical analysis of all data.

\section{REFERENCES:}

[1] Landewé RB, Machado PM, Kroon F, et al. EULAR provisional recommendations for the management of rheumatic and musculoskeletal diseases in the context of SARS-CoV-2. Ann Rheum Dis. 2020;79(7):851-858. doi:10.1136/ annrheumdis-2020-217877

[2] Strangfeld A, Schäfer M, Gianfrancesco MA, et al. Factors associated with COVID-19-related death in people with rheumatic diseases: results from the COVID-19 Global Rheumatology Alliance physician-reported registry [published online ahead of print, 2021 Jan 27]. Ann Rheum Dis. 2021;annrheumdis-2020-219498. doi:10.1136/annrheumdis-2020-219498

Disclosure of Interests: None declared

DOI: 10.1136/annrheumdis-2021-eular.3445

\section{POS1245 MORTALITY OF COVID-19 IN PATIENTS WITH RHEUMATIC DISEASES: COMPARISON TO THE GENERAL POPULATION IN MÉXICO}

M. U. Martínez-Martínez ${ }^{1}$, F. Irazoque-Palazuelos ${ }^{2}$, T. S. Rodriguez-Reyne ${ }^{3}$, E. Zamora ${ }^{4}$, A. Castillo Ortiz ${ }^{5}$, B. E. Zazueta ${ }^{6}$, S. Duran Barragan ${ }^{7}$, M. RullGabayet $^{3}$, J. F. Moctezuma-Ríos ${ }^{8}$, X. Jimenez Jimenez ${ }^{9}$, E. Martin-Nares ${ }^{3}$, D. Cervantes-Rosete ${ }^{3}$, D. Vega-Morales ${ }^{10}$, D. X. Xibille Friedmann ${ }^{11}$, A. Barragán-Garfías ${ }^{9}$, E. Alvarez Hernandez ${ }^{8}$, M. Vázquez-Del Mercado Espinosa $^{12}$, C. F. Pacheco Tena ${ }^{13}$, D. Alpizar-Rodriguez ${ }^{14}$ on behalf of Mexican Study group of COVID-19 in Rheumatic diseases. ${ }^{1}$ Instituto Mexicano del Seguro Social, Internal Medicine, Rioverde, Mexico; ${ }^{2}$ Centro de Investigación y Tratamiento Reumatológico S.C., Rheumatology, Mexico City, Mexico; ${ }^{3}$ Instituto Nacional de Ciencias Médicas y Nutrición Salvador Zubiran, Immunology and Rheumatology, Mexico City, Mexico; ${ }^{4}$ Centro Médico de Pensiones, Rheumatology, Merida, Mexico; ${ }^{5}$ Private Practice, Rheumatology, Merida, Mexico; ${ }^{6}$ Private Practice, Rheumatology, Mexicali, Mexico; ${ }^{7}$ Clínica de Investigación en Reumatología y Obesidad, Rheumatology, Guadalajara, Mexico; ${ }^{8}$ Hospital General de México 'Dr. Eduardo Liceaga', Rheumatology, Mexico City, Mexico; ${ }^{9}$ Private Practice, Rheumatology, Mexico City, Mexico; ${ }^{10}$ Private Practice, Rheumatology, Monterrey, Mexico; ${ }^{11}$ Servicios de Salud de Morelos, Departamento de Investigación y Capacitación, Cuernavaca, Mexico; ${ }^{12}$ Hospital Civil de Guadalajara "Juan I. Menchaca”, Rheumatology, Guadalajara, Mexico; ${ }^{13} \mathrm{Facultad}$ de Medicina y Ciencias Biomédicas, Rheumatology, Chihuahua, Mexico; ${ }^{14}$ Colegio Mexicano de Reumatología, Research Unit, Mexico City, Mexico

Background: COVID-19 outcomes in Mexican patients with rheumatic diseases (RDs) in comparison to general population patients are unknown.

Objectives: To compare mortality and hospitalization of COVID-19 patients with RDs and those without

Methods: We included for this study all the Mexican patients with RDs and COVID-19 registered from April $17^{\text {th }}$ to October $30^{\text {th }}, 2020$ in the COVID-19 Global Rheumatology Alliance registry. We compare clinical and demographic characteristics of patients with RDs and COVID-19 to patients with COVID19 that were selected randomly from the Mexican Epidemiology database (1:3). A logistic regression analysis was performed to adjust for confusion variables.

Results: We included 322 patients with COVID-19 and RDs and 969 controls without RDs. Table 1 shows the demographic characteristics and comorbidities of both groups. Bivariate analysis showed that patients with RDs had higher mortality, were older, and were more frequently hospitalized. Comorbidities, such as diabetes, hypertension, cardiovascular and renal diseases were also more frequent in patients with RDs. In the multivariate analysis, having a RD was no longer associated with mortality (Figure 1). 